\title{
Cytokinin- microbiome interactions regulate developmental functions
}

Rupali Gupta ${ }^{1}$, Dorin Elkabetz ${ }^{1,2}$, Meirav Leibman-Markus ${ }^{1}$, Elie Jami ${ }^{3}$, and Maya $\operatorname{Bar}^{1 \&}$

${ }^{1}$ Department of Plant Pathology and Weed Research, Plant Protection Institute, Agricultural Research Organization, Volcani Institute, Rishon LeZion, Israel.

${ }^{2}$ Department of Plant Pathology and Microbiology, Hebrew University of Jerusalem, Rehovot, Israel

${ }^{3}$ Department of Ruminant Science, Animal Science Institute, Agricultural Research Organization, Volcani Institute, Rishon LeZion, Israel.

${ }^{\&}$ Corresponding author: Dr. Maya Bar, Email: mayabar@volcani.agri.gov.il

Dr. Maya Bar is responsible for distribution of materials integral to the findings presented in this article in accordance with the policy described in the Instructions for Authors (www.plantcell.org).

Short title: Cytokinin exerts developmental functions through the microbiome

Keywords: Bacillus, Cytokinin, Microbiome, Morphogenesis, Plant Growth Promotion, Plant Development 


\section{ABSTRACT}

The interaction of plants with the complex microbial networks that inhabit them is important for plant health. While the reliance of plants on their microbial inhabitants for defense against invading pathogens is well documented, the acquisition of data concerning the relationships between plant developmental stage or aging, and microbiome assembly, is still underway. In this work, we observed developmental-age dependent changes in the phyllopshere microbiome of tomato. The plant hormone cytokinin (CK) regulates various plant growth and developmental processes. Here, we show that age-related shifts in microbiome content vary based on content of, or sensitivity to, CK. We observed a developmental age associated decline in microbial richness and diversity, accompanied by a decline in the presence of growth promoting and resistance inducing bacilli in the phyllosphere. This decline was absent from CK-rich or CK-hypersensitive genotypes. Bacillus isolates we obtained from $\mathrm{CK}$ rich genotypes were found to re-program the transcriptome to support morphogenesis and alter the leaf developmental program when applied to seedlings, and enhance yield and agricultural productivity when applied to mature plants. Our results support the notion that CK-dependent effects on microbiome content support developmental functions, suggesting that these are mediated by $\mathrm{CK}$ in part via the bacterial community. 


\section{INTRODUCTION}

The phyllosphere microbial community plays positive roles in host plant life. 2

Disease resistance, abiotic stress tolerance, improved vigor and alterations in 3

life cycle phenology have been documented in the presence of specific 4

bacterial communities (Koskella, 2020; Liu et al., 2020). The plant leaf niche 5

occupies a large surface area, and is important for the plant microbial 6

community structure and function. The agricultural and ecological implications 7

of plant-beneficial interactions with microbes have motivated intense 8

investigation into the factors that shape phyllopshere microbiota (French et 9

al., 2021). Deciphering the factors underlying the composition and dynamics 10

of microbiome assembly is a key step towards understanding how the 11

microbial community affects plant health and development. 12

In terms of diversity and richness, the phyllosphere hosts complex microbial 13

communities that are determined by several dynamic factors, such as plant 14

age, plant genotype, environmental variables, geographical location and 15

agricultural practices (Vorholt, 2012; Leveau, 2019). Previous work has 16

uncovered factors that are central in determining the composition of 17

microbiota. In particular, plant genotype has been identified to be an important 18

driver that influences the structure of the phyllopshere microbiome 19

(Bodenhausen et al., 2014; Wagner et al., 2016). In addition to host genotype, 20

geographic growth location has also been defined as a dominant factor 21

influencing community structure. For instance, perennial plants belonging to 22

the same species grown in different geographic locations showed surprisingly $\quad 23$

similar leaf microbial communities than different plant species grown in close $\quad 24$

proximity (Redford et al., 2010). Recently, (Li et al., 2021) found that 25

phyllosphere specificity varied more with respect to growth stage than to 26

genotype of Arabidopsis thaliana. The growth stage and genotype of $A .27$

thaliana are crucial in shaping phyllosphere bacterial composition, with the 28

former being a stronger driver. Many studies on the structure of plant- 29

associated microbial communities have shown that plants grown in sterile 30

conditions house microbes that resemble airborne communities, while plants 31

grown in natural conditions often have phyllosphere communities comprised 32

of soil microbiota (Bodenhausen et al., 2014; Maignien et al., 2014). Thus, 33 
from previous studies it becomes evident that the phyllopshere microbiome 34 structure is complex, being influenced by various dynamic factors. 35 Growth stage- or age dependent bacterial community shifts in the rhizosphere 36 have been well documented (Chaparro et al., 2014; Cordovez et al., 2021). 37 The phyllosphere microbiome also undergoes dynamic changes as plants 38 develop and/or age, as shown in Arabidopsis, Lactuca sativa and Boechera 39 stricta (Williams et al., 2013; Wagner et al., 2016; Berens et al., 2019) These 40 age-related shifts in microbial content are presumably linked with age- 41 dependent changes in the plant, such as hormonal and/ or physiological 42 variation. Plant aging differentially affected the abundance of multiple leafassociated microbial taxa such as Actinobacteria, Armatimonadetes and 44 Verrucomicrobia, at various sites in Boechera stricta (Wagner et al., 2016). In 45 the phyllopshere, age-related microbiome differentiation may be associated 46 with the differences in the leaf structure or geometry, cuticle structure, 47 trichome placement, or composition of the volatile substances secreted by the 48 leaf. We recently reported that leaf structural niches influence phyllosphere microbial content in different genotypes (Gupta et al., 2021).

Plant age and developmental status are important factors influencing host 50 immune responses (Develey-Rivière and Galiana, 2007; Berens et al., 2019). 51 (Redford et al., 2010). Plants have been shown to have differential age52 dependent immune responses at the organ level (Zeier, 2005). In A. thaliana, 54 young rosette leaves exhibit greater SA accumulation and SA-mediated 55 resistance than older rosette leaves (Zeier et al., 2005). Age-dependent 56 fluctuations in host resistance can assist plants in prioritizing the protection of 57 valuable tissues, such as young leaves (McCall and Fordyce, 2010). 58 However, little is known about the relationships between plant growth or 59 developmental stage, and bacterial communities in the phyllosphere.

The plant hormone cytokinin (CK) regulates various developmental 61 processes, including embryogenesis, cell division and differentiation, shoot 62 and root apical meristem maintenance, shoot and root lateral organ formation, 63 and many others (Kieber and Schaller, 2018; Gupta et al., 2021). Thus, it is 64 not surprising that changing endogenous CK content or signaling would cause 65 alterations to plant development, resulting in changes to organ structure and 66 
patterning. CK has been demonstrated to promote morphogenesis and delay differentiation during plant development in many different plant species and 68 developmental contexts (DeMason, 2005; Nikolić et al., 2006; Marsch- 69 Martínez et al., 2012; Li et al., 2013; Israeli et al., 2021), likely by delaying the 70 differentiation of meristematic cells (Bartrina et al., 2011). Tomato plants with 71 altered CK content have altered developmental programs, and modified organ 72 structures. Overexpressing the CK biosynthesis gene ISOPENTENYL 73 TRANSFERASE7 (IPT7), resulting in elevated endogenous levels of CK 74 (Shani et al., 2010), or mutating in the MYB transcription factor CLAU, 75 resulting in increased CK sensitivity (Bar et al., 2016), results in highly 76 patterned and complex leaves, Concomitantly, decreasing endogenous levels 77 of CK by overexpressing CK OXIDASE3 (CKX3) (Shani et al., 2010), results 78 in simplified leaves bearing less organs (Shwartz et al., 2016).

Recently, investigating the relationship between CK and the phyllosphere 80 microbiome, we demonstrated that $\mathrm{CK}$ acts as a selective force in microbiome 81 assembly, increasing richness, and promoting the presence of Firmicutes 82 (Gupta et al., 2021). We found CK-mediated immunity to partially depend on 83 the microbial community. Bacilli we isolated from CK-rich or CK- 84 hypersensitive plant genotypes, induced plant immunity, and promoted 85 disease resistance. Using biomimetics, we found that bacilli are preferentially 86 supported on leaves high in CK content or signaling, due to the altered leaf 87 structures present in theses genotypes.

Following our previous study, one of the main unanswered questions that 89 arose was, given that CK-mediated immunity is dependent in part on the 90 microbiome, and that $\mathrm{CK}$ is a driving force in microbiome assembly, could CK- 91 mediated developmental processes also be dependent on the microbiome? In 92 the present study, we investigated developmental-age dependent changes in 93 the microbiome. We found that age-related shifts in microbiome content vary 94 based on CK content/ sensitivity. Bacterial isolates from CK rich genotypes 95 were found to re-program the transcriptome to support morphogenesis and 96 alter the developmental program when applied to seedlings, and increase 97 yield and productivity when applied to older plants. Our results suggest that 98 CK-dependent effects on microbiome content and assembly support 99 
bioRxiv preprint doi: https://doi.org/10.1101/2021.08.02.454802; this version posted August 2, 2021. The copyright holder for this preprint

(which was not certified by peer review) is the author/funder, who has granted bioRxiv a license to display the preprint in perpetuity. It is made available under aCC-BY-NC-ND 4.0 International license.

developmental functions, in line with our previous reports that CK functions

100

are mediated via the bacterial community. 
bioRxiv preprint doi: https://doi.org/10.1101/2021.08.02.454802; this version posted August 2, 2021. The copyright holder for this preprint (which was not certified by peer review) is the author/funder, who has granted bioRxiv a license to display the preprint in perpetuity. It is made available under aCC-BY-NC-ND 4.0 International license.

104 
To examine the effect of plant developmental stage on phyllosphere composition, microbial DNA was prepared from the phyllosphere of randomly interspersed tomato (S. lycopersicum M82) seedlings (10 days post germination), vegetative plants (3 weeks post germination) and reproductive flowering plants ( 6 weeks post germination), grown in a net house in the winter of 2018. When examining community structure between the samples using weighted UniFrac distances, we observed a significant clustering of the samples based on their developmental stage, demonstrating that the distance among biological replicates is significantly smaller within groups then between groups (Figure 1A,B). Interestingly, distances between the samples of the same age also decreased in parallel to the increase in developmental age, with the smallest distance observed in the oldest, reproductive group. Community richness (Figure 1C), Shannon index (Figure 1D), and proportion of Firmicutes in the bacterial community (Figure 1E), also all decreased as developmental age increased, while the proportion of Proteobacteria in the bacterial community increased with aging (Figure 1F).

The amount of bacilli in the bacterial community changes throughout

We previously demonstrated that high CK content, or increased CK sensitivity, support an increase in phyllosphere community richness, Shannon index, and in the proportion of Firmicutes (Gupta et al., 2021). Generally, CKs are thought to be synthesized mainly in the roots and transported via the xylem to the shoots, where they exert developmental functions (Davey and van Staden, 1976; Kaminek et al., 1997). We hypothesized that the increased numbers of bacilli present in the bacterial community in seedlings (Figure 1) may be supported by the increased levels of CKs present in young leaves, levels which decline over time (Nordstrom et al., 2004), in accordance with the age-related decrease in Firmicutes we observed (Figure 1E). We examined 

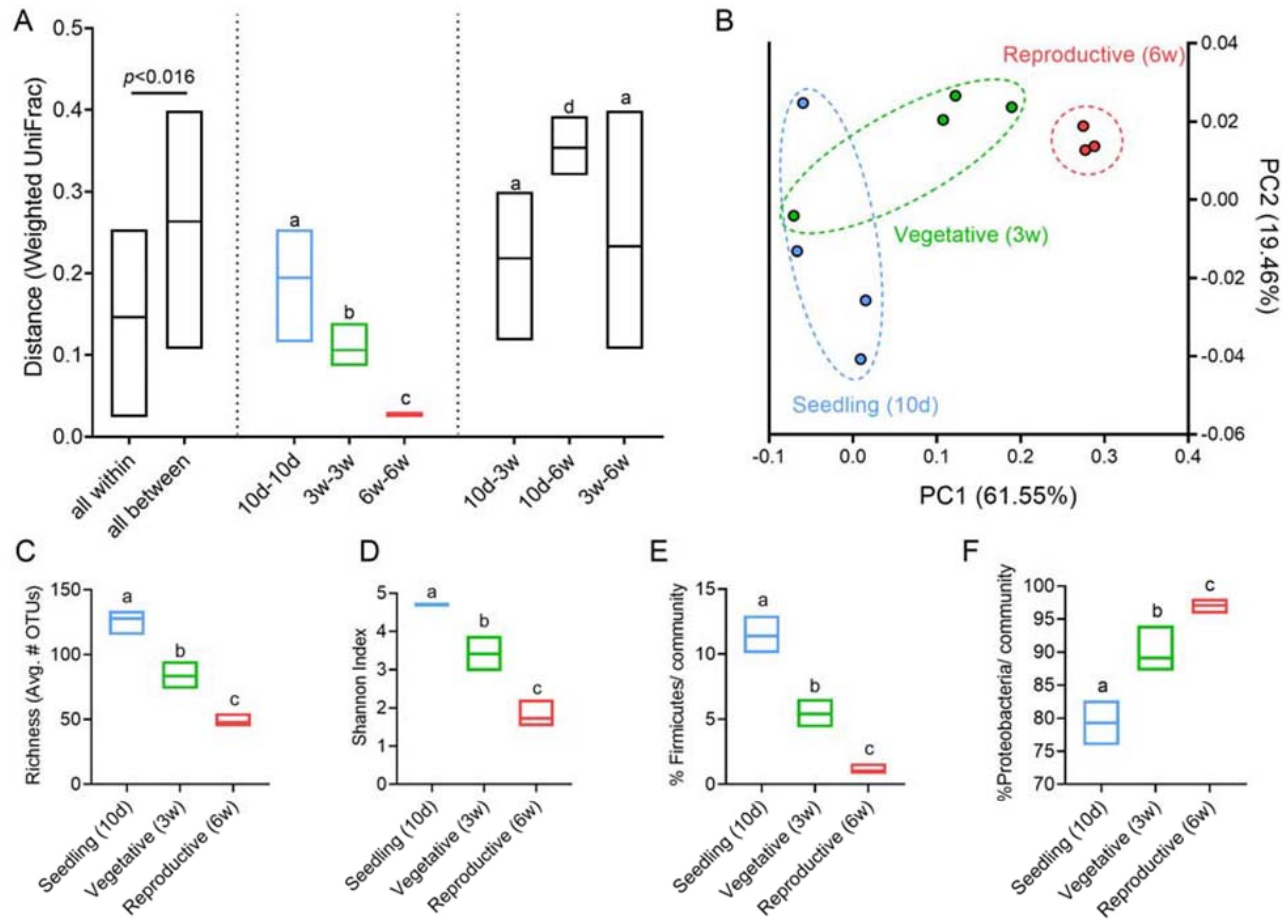

$\mathrm{F}$

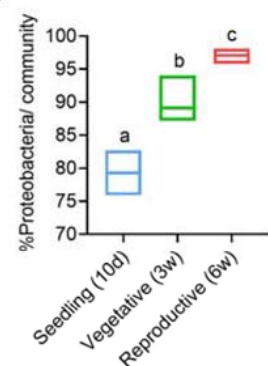

Figure 1. Developmental aging is accompanied by a decrease in bacterial community diversity, richness, and firmicute content.

16S rRNA sequencing of the bacterial phyllosphere of randomly interspersed S. lycopersicum M82 plants grown in a net house in the winter of 2018, N=4 for each genotype, of different ages: "Seedling" (10 days old), "Vegetative" ( 3 weeks old), and "Reproductive" ( 6 weeks old).

A Weighted UniFrac beta diversity. Distance is significantly smaller within groups then between groups $(p<0.016)$. B Principal coordinates analysis of distance between all individual samples in the weighted UniFrac beta diversity calculations. C Species richness- alpha diversity. D Shannon index. E Proportion of Firmicutes in the bacterial community of indicated genotypes. $F$ Proportion of Proteobacteria in the bacterial community of indicated genotypes.

Floating bars encompass minimum to maximum values, line indicates mean. Different letters indicate statistical significance between samples in a two-tailed t-test with Welch's correction. C $p<0.0073$; D $p<0.04 ; \mathrm{E} p<0.0045 ; \mathrm{F} p<0.0007$.

seedlings and mature plants, in M82 and high and low CK content genotypes, overexpressing $p B L S \gg>I P T$ or $p F I L \gg>C K X$, as well as in the high $C K$ sensitivity mutant clausa. As shown in Figure 2, while bacilli decrease with developmental aging in M82, in the altered CK genotypes, bacilli percentage in the microbial community does not change with age. $p F I L \gg>I P T$ and clausa have increased percentages of bacilli in the microbial community in both the seedling (Figure 2A, B) and mature (Gupta et al., 2021), Figure 2A,C) stages, and, unlike in the background M82 (Figures 1, 2A), the proportion of 


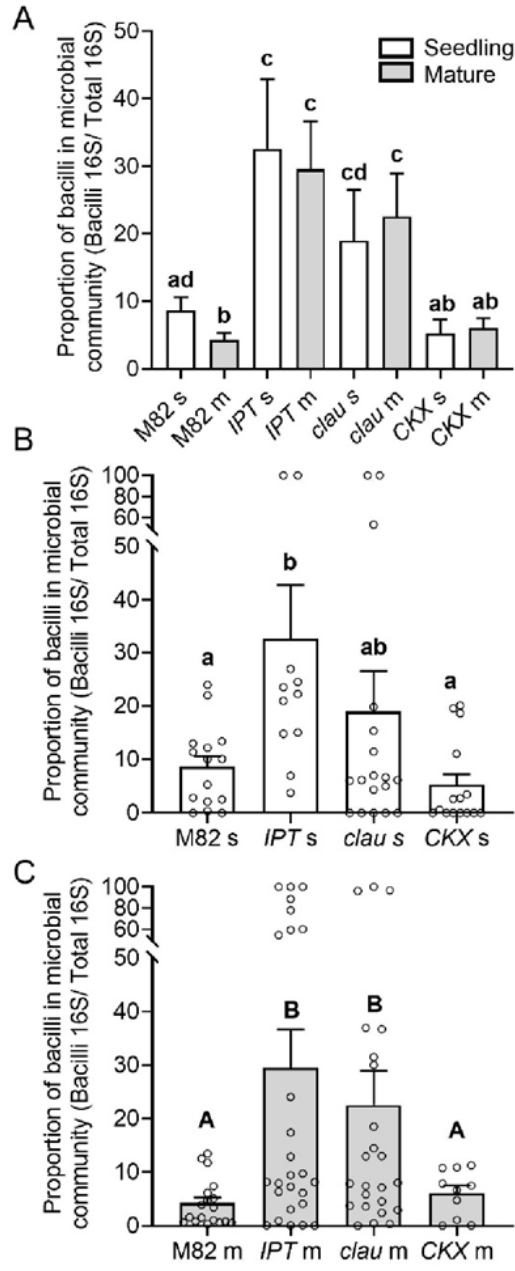

Figure 2. CK prevents age-associated decrease in bacilli content in the bacterial community.

Bacterial DNA was extracted from indicated genotypes at the seedling (15-day old, indicated with "s" and white bars) and mature plant (45-day old, indicated with " $\mathrm{m}$ " and gray bars) stages. Bacilli amounts were estimated by qPCR of the bacillus $16 \mathrm{~S}$ rRNA gene, normalized to qPCR of the total 16S rRNA gene content. (A) Comparison of bacilli content in the background M82, the high CK content IPT, the high CK sensitivity clau, and the low CK content CKX, at both seedling and mature stages. (B) Comparison of the different genotypes at the seedling stage, all points shown. (C) Comparison of the different genotypes at the mature stage, all points shown. Graphs depict mean $\pm S E$. Different letters indicate statistically significant differences in an unpaired two-tailed t-test with Welch's correction, $\mathrm{N}=10$. (A) $p<0.048$. (B) $p<0.043$. (C) $p<0.018$.

bacilli in the bacterial community does not decrease in mature plants when 145 compared with seedlings. In accordance with our previous results (Gupta et 146 al., 2021), we also observed higher amounts of microbial DNA in $p B L S>>I P T$, and lower amounts in $p F I L>>C K X$, suggesting that these genotypes also support increased or decreased amount of bacteria in general, respectively

\section{Phylloshpere isolated bacilli from high-CK genotypes accelerate development}

Bacilli are well known to have growth-promoting effects (Miljaković et al., 

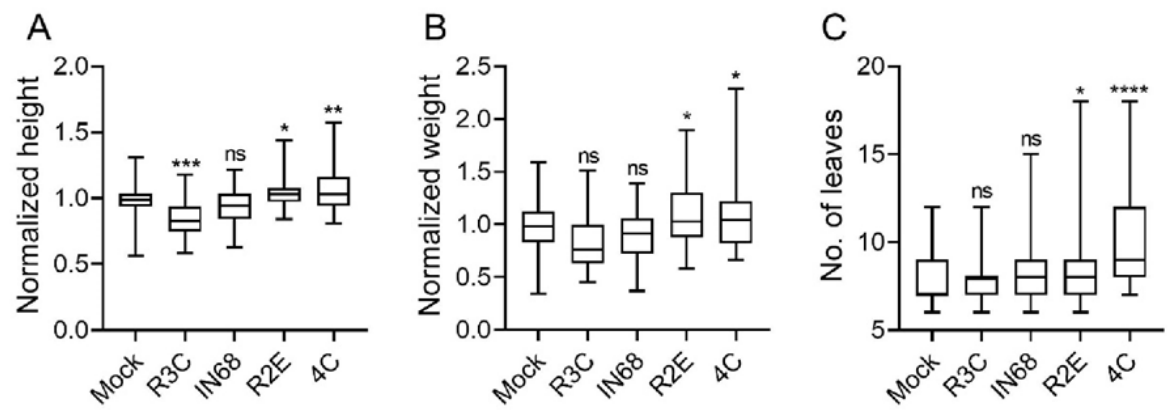

Figure 3. Bacilli isolated from high-CK genotypes affect development in seedlings.

S. lycopersicum cv. M82 seedlings were treated with indicated bacteria $\left(\mathrm{OD}_{600}=0.1\right)$, once a week for 2 weeks, starting from cotyledon emergence. Developmental parameters were measured in 10 day old M82 mock and bacterial isolate treated seedlings. (A) Seedling height (root crown to main shoot apical meristem) in centimeters. (B) Seedling weight. (C) Number of leaves produced starting from P1 (all initiated leaves were counted by dissecting the shoots).

Boxplots depict minimum to maximum values, with box indicating inner quartile ranges and whiskers representing outer quartile ranges. Lines in box indicates median. Five independent experiments were conducted. Asterisks represent statistical significance from mock treatment in a one-way ANOVA with a Tukey post-hoc test (A-B), or a two-tailed t-test with Welch's correction (C). ${ }^{*} p<0.05,{ }^{* *} p<0.01$, ${ }^{* * *} p<0.001, * * * * p<0.0001, \mathrm{~ns}=$ non significant. $\mathrm{A} \mathrm{N}=65, p<0.041 . \mathrm{B} \mathrm{N}=50, p<0.047 . \mathrm{C}=70, p<0.029$.

content genotype, finding them to promote plant immunity and disease

resistance (Gupta et al., 2021). Given that seedlings, which are more

morphogenetic, rapidly generating new organs, and growing at a faster pace

than mature plants, have more $\mathrm{CK}$ and support more bacilli, we next

investigated whether our phyllosphere bacilli isolates could affect seedling

development. We examined the early development of tomato seedlings

following treatment with different bacterial isolates. We found that two

bacterial treatments, one at cotyledon emergence, and the second after one

week, were sufficient to induce accelerated growth and generation of leaves

in the treated seedlings, in the case of the two bacilli isolates R2E and $4 \mathrm{C}$

(Figure 3A-C). This treatment regimen also had a negative effect on growth in

In addition to the growth and organ initiation promoting effects, we observed

(Figure 3) changes to the plant developmental program following bacterial 

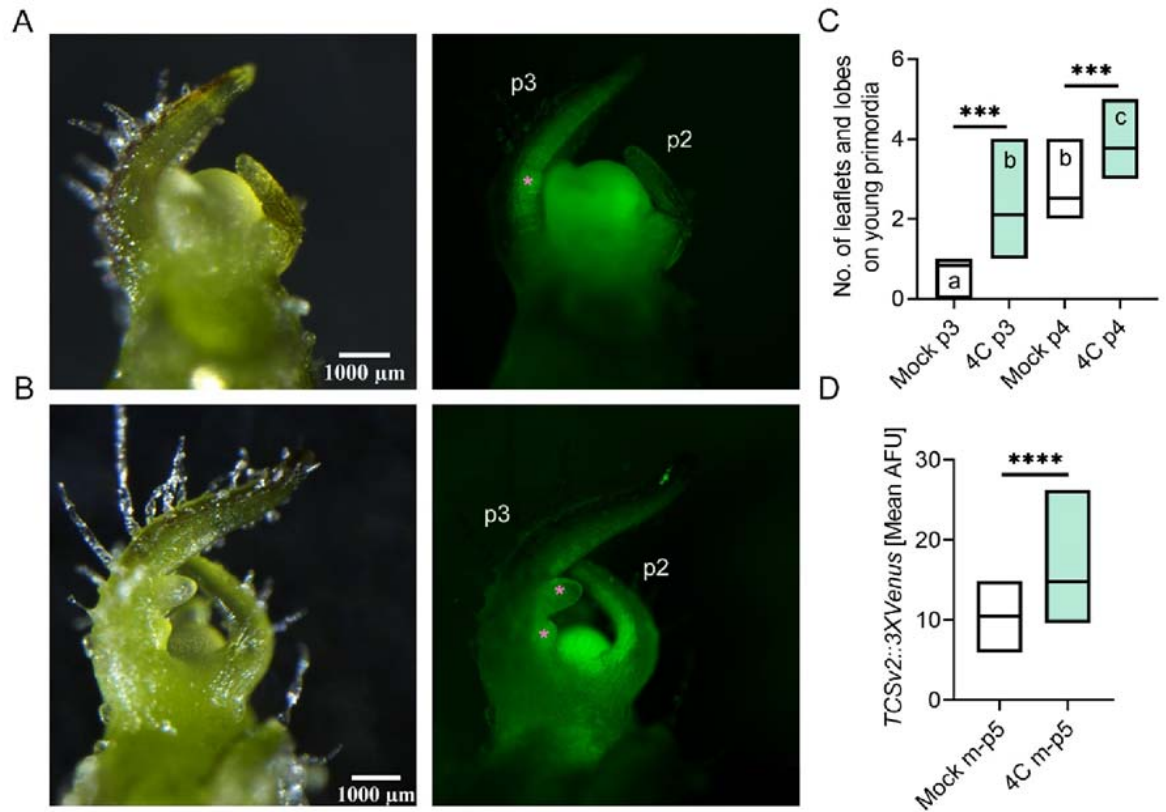

Figure 4. B. megaterium $4 \mathrm{C}$ accelerates leaf development and increases $\mathrm{CK}$ pathway activation.

S. lycopersicum cv. M82 seedlings were treated with indicated bacteria $\left(\mathrm{OD}_{600}=0.1\right)$, once a week for 2 weeks, starting from cotyledon emergence. Leaf complexity and TCSv2::3XVenus expression were measured in 10 day old M82 mock and $4 \mathrm{C}$ treated plants. (A) Typical Mock treated shoot apical meristem (SAM) and three youngest leaf primordia (p1-p3). Bar=1000 $\mu \mathrm{m}$. (B) Typical B. megaterium $4 C$ treated SAM and p1-p3. P2 and p3 are indicated in the Venus fluorescence images, with asterisks indicating the nascent leaflets on p3. (C) Number of leaflets and lobes produced on p3 and p4. (D) TCSV2 driven total Venus fluorescence was measured as mean arbitrary fluorescent units (AFU) in images captured under identical conditions in shoots comprising the 5 youngest primordia. Each primordia was quantified for leaflet number and TCS expression when Leaf No. 5 was at that developmental stage- all quantifications were done on the fifth leaf as it developed.

C-D Floating bars depict minimum to maximum values, with lines indicating mean. Three independent experiments were conducted. Asterisks represent statistical significance from mock treatment, and different letters represent statistically significant differences among samples, in a one-way ANOVA with a Dunnett post-hoc test (C), or in a two-tailed t-test (D). ${ }^{* * *} p<0.001,{ }^{* * * *} p<0.0001 . \mathrm{C} \mathrm{N}=12$, $p<0.0002$. $\mathrm{D} \mathrm{N}=21, p<0.0001$.

increased the number of leaves produced (Figure 3C). We therefore chose to

program in S. lycopersicum M82 (Shani et al., 2010; Israeli et al., 2021), in primordium (p3), in mock plants and plants treated with 4C. P3 was chosen 
results in a significant increase in leaf patterning (Figure 4A-C). Leaf

complexity over time was also examined upon B. megaterium $4 \mathrm{C}$ or $B$.

pumilus R2E treatment in seedlings (Figure S3). We found that both R2E and

4C increase leaf complexity (Figure S3), with 4C doing so earlier. Leaf

plants when comparing the first and last time points among mock treatments,

Bacillus treatment activates the CK response machinery and

Using the CK activity response synthetic promoter TCS (two-component

To further characterize the effect of bacterial isolates on development, we 
A

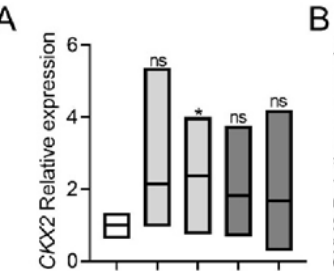

C

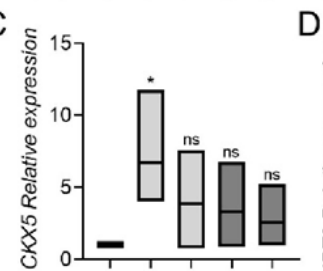

$\mathrm{E}$

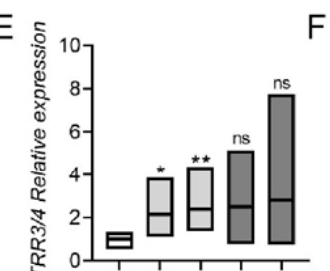

G

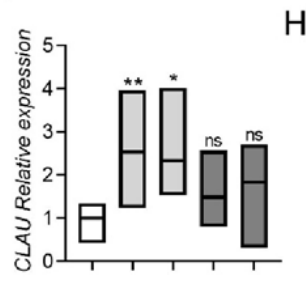

I

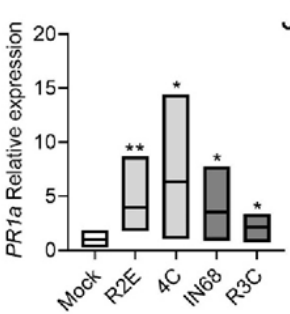

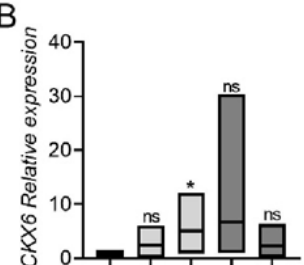

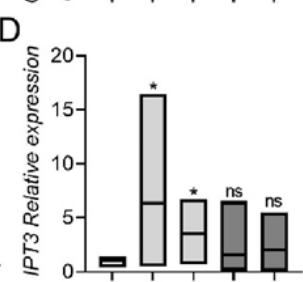

$\mathrm{F}$

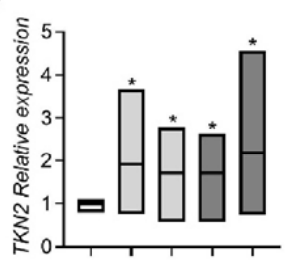

$\mathrm{H}$
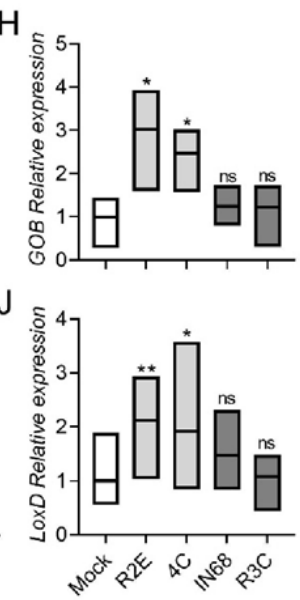

Figure 5. Bacilli from high-CK genotypes differentially activate morphogenetic genes and $\mathrm{CK}$ pathway genes.

S. lycopersicum cv. M82 plants were pre-treated with indicated bacteria $\left(\mathrm{OD}_{600}=0.1\right)$ once a week, two treatments in total, starting from cotyledon emergence. Gene expression was assayed by qRT-PCR, 3 days after the second treatment.

Floating bars indicate minimum to maximum values (box) with mean (line in box). Bacilli are indicated in pale gray bars, gram negative bacteria in dark gray bars. Genes were normalized to a geometric mean of the expression of 3 normalizers: SIExp, SICYP, and SIRPL8.

A- SICKX2; B- SICKX6; C- SICKX5; D- SIIPT3; ESITRR3/4; F- SITKN2; G- SICLAU; H- SIGOB; ISIPR1a; J- SILOXD. Asterisks indicate statistical significance from Mock treatment in an unpaired two-tailed t-test with Welch's correction, $\mathrm{N}=6, p<0.05$. ( ${ }^{*} p$ value $<0.05 ;{ }^{* *} p$ value $<0.01$; ns- non significant).

5H) (Bar et al., 2015). To verify the response to bacterial treatment, we examined SA pathway activation using PR1a (Figure 5I) (Gupta et al., 2020), and JA pathway activation using LoxD (Figure 5J) (Dimopoulou et al., 2019).

We found that all isolates activated the SA pathway (Figure 5I), however, 220 interestingly, only the bacilli isolates activated the JA pathway (Figure $5 \mathrm{~J}$ ).

Phylloshpere isolated bacilli from high-CK genotypes promote growth and increase agricultural productivity in mature plants

Since we found that bacilli isolates from high-CK genotypes accelerated 

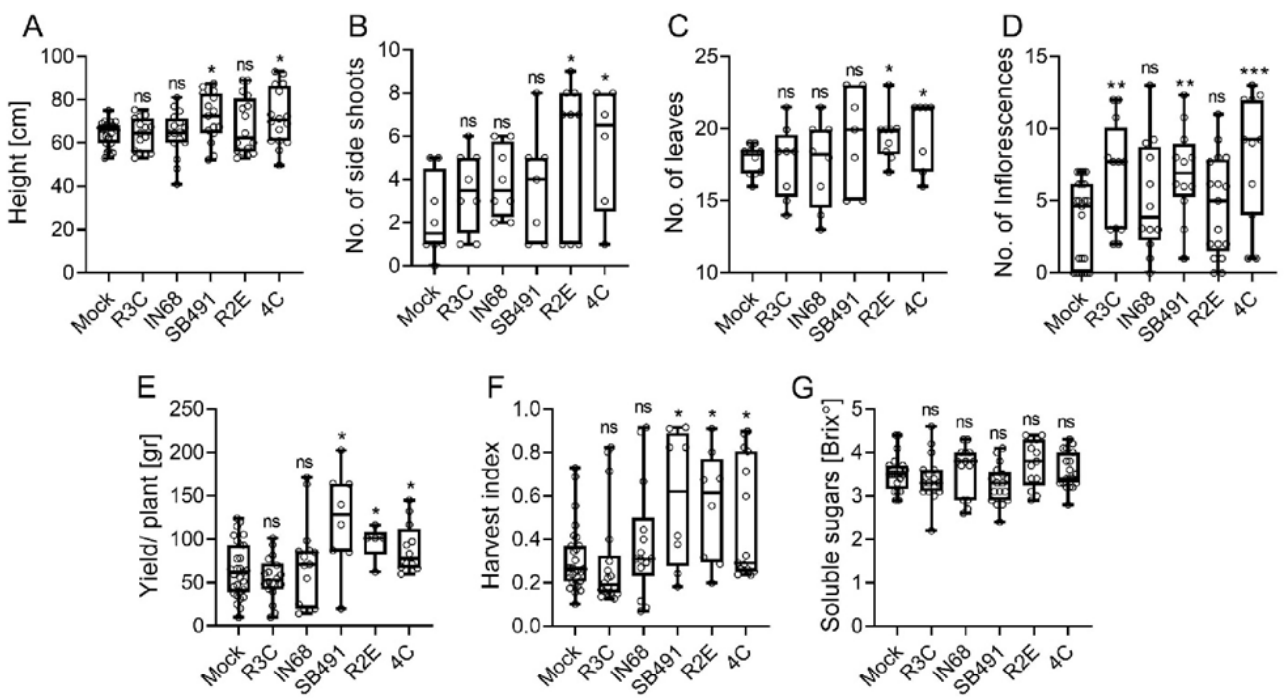

Figure 6. Bacilli from high-CK genotypes increase agricultural productivity.

3 week-old S. lycopersicum cv. M82 plants were treated with indicated bacteria $\left(\mathrm{OD}_{600}=0.1\right)$, once a week for 4 weeks. Agricultural parameters were measured in M82 mock and bacterial isolate treated plants, just prior to harvest (65-75 days after germination). (A) Plant height (root crown to main shoot apical meristem) in centimeters. (B) Number of side shoots used as a measure of apical dominance. (C) Number of leaves produced. (D) The average number of inflorescences per plant. (E) Average yield, expressed as the total fruit weight per plant in grams. (F) Harvest index (HI), calculated as the ratio between the total mass of fruit yield and the total biomass. (G) Total soluble sugars were measured using a refractometer and are expressed as ${ }^{\circ}$ Brix.

Boxplots depict minimum to maximum values, with box indicating inner quartile ranges and whiskers representing outer quartile ranges. Lines in box indicates median. Four independent experiments were conducted. Asterisks represent statistical significance from mock treatment in a two-tailed t-test with Welch's correction, ${ }^{*} p<0.05,{ }^{*} p<0.01,{ }^{* * *} p<0.001$. A N $=16, p<0.035$. B N=8, $p<0.033$. C N=8, $p<0.05$. $\mathrm{D} \mathrm{N}=12, p<0.0095$. E N=9, $p<0.037$. $\mathbf{F ~ N}=9, p<0.043$. $\mathbf{G ~ N}=12$, ns=non significant.

affect growth and agricultural productivity in older plants. Several instances of agricultural use for bacilli have been reported (reviewed in (Miljaković et al., 2020). Treatment with the bacillus isolate $B$. megaterium $4 C$ increased plant height (Figure 6A) and decreased apical dominance (Figure 6B), increased 230 the number of leaves (Figure 6C), number of inflorescences (Figure 6D), as well as the average yield per plant (Figure 6E) and harvest index (Figure 6F). Treatment with the bacillus isolate $B$. pumilus R2E decreased apical dominance (Figure 6B), and increased the number of leaves (Figure 6C), as well as the average yield per plant (Figure 6E) and harvest index (Figure 6F), but did not affect plant height (Figure 6A) or the number of inflorescences (Figure 6D). The gram negative controls, R. picketti R3C and Pseudomonas aeruginosa IN68, had no effect on agricultural parameters, except for an 
increase in the number of observed inflorescences with IN68 (Figure 6D). A 239

control B. subtilis lab strain, SD491, also increased some of the tested 240

agricultural parameters vis., height (Figure 6A), number of inflorescences

(Figure 6D), yield (Figure 6E), and harvest index (Figure 6F). None of the 
Developmental status/ aging influence the phyllopshere microbial community

Studies of the driving forces underlying microbial community formation have content and assembly (Bodenhausen et al., 2014; Li et al., 2021), depending on the context of the study. Despite recent progress in our understanding of the phyllosphere microbiome, much of the variation found in the phyllosphere remains unsolved, suggesting that the driving forces shaping microbial bacterial phyllosphere community dynamics throughout plant developmental stages revealed significant changes to community richness and diversity

(Figure 1). These results are in agreement with earlier reports concerning succession of microbial communities in the phyllosphere (Wagner et al., 2016; changes in the conditions required for survival, succession, persistence, and colonization of different microbial taxa, may occur during plant development and growth. These factors were previously reported to be important in 
(Shwartz et al., 2016). Overexpression of the CK biosynthesis gene AtIPT7 in

tomato leaves leads to the formation of highly complex leaves, whereas

overexpression of the $\mathrm{CK}$ oxidase/degradation gene $C K X$, results in reduced

(Bar et al., 2016). Recently, we found that increased CK content, as in $p B L S>>I P T 7$, or sensitivity, as in clausa, can have a strong effect on shaping the microbiome (Gupta et al., 2021). We found that high CK content or signaling increased species richness while reducing distances among samples within high-CK genotypes, resulting in dominant and consistent with CK promoting growth of some bacilli in vitro (Gupta et al., 2021).

Here, we analyzed the content of phyllosphere microbiota from genotypes with different CK content or sensitivity, at the seedling and mature was lower in WT M82 and pFIL>>CKX than in pBLS>>IPT and clausa at both previous microbiome analysis of these genotypes (Gupta et al., 2021). Interestingly, examination of the microbiome shift between these two developmental stages with respect to bacilli content in high-CK and low-CK genotypes showed that, while bacilli spp. content decreases with age in the background M82, bacilli remain in high amounts in the CK-rich genotypes taking place in the shoot, and the amount of CK translocated from the roots. 
increased numbers of bacilli present in the microbial community in seedlings.

These increased CK levels decline over time as the plant matures (Albacete

Therefore, although distinct changes in structural leaf microenvironments are highly likely, it is also possible that the abundance of CK present in phyllosphere.

\section{Bacilli isolated from high-CK genotypes can alter developmental programs and increase plant productivity}

The microbiome has been demonstrated to be required for achieving predictable developmental outcomes, as plants in sterile or axenic environments often grow more slowly and have altered development (Kremer, 
supporting growth (Figure 6), suggesting a positive, rather than negative, 346 correlation between growth and defense when tomato plants are treated with these bacteria. This could indicate an agricultural advantage to treatment with certain bacilli isolated at specific regimens, and will be investigated further.

Our results indicate that the growth promotion exerted by bacilli strains isolated from high-CK environments are the result of alterations to developmental programs (Figures 3-4, S2-S3). During leaf development, the young leaf undergoes morphogenesis and reaches the mature, differentiated stage of its development simultaneously with the decline in its morphogenetic potential. Compound leaves of tomato are composed of multiple leaflets, which initiate basipetally from a meristematic region at the leaf margin known as the marginal blastozone (Shani et al., 2010; Hagemann and Gleissberg, 1996; Steiner et al., 2020). The leaf morphogenetic potential is harbored by meristematic cells, which respond to $\mathrm{CK}$ and therefore exhibit TCS activation. TCSV2 driven expression was observed in an expanded region in $B$. megaterium 4C treated tomato seedlings in the shoot apical meristem (SAM) and three youngest leaf primordia (p1-p3), demonstrating that CK pathway activation during leaf development was increased upon $B$. megaterium treatment (Figure 4A,B,D). In parallel, leaves from bacillus treated plants displayed an increase in patterning, exhibiting 1-2 additional organs than typically observed on leaves of a similar developmental plastochron (Figure 4A,B,C), confirming that morphogenesis is indeed promoted by $B$.

CK pathway genes regulate the activity of meristems (Bartrina et al., 2011).

The KNOXI gene Tkn2, plays important role in promoting leaf morphogenesis by delaying differentiation, preserving the meristematic identity of the leaf margin. The NAM-CUC transcription factor GOBLET determines boundaries within meristematic regions, that are necessary for organ initiation (Berger et al., 2009; Bar et al., 2016) While the MYB transcription factor CLAU regulates the exit from the morphogenetic phase of tomato leaf development by affecting the CK/ GA balance (Israeli et al., 2021). The changes in the expression levels of these genes upon treatment with bacilli isolated from high-CK genotypes (Figure 5) further supports the notion that these particular 
promotion of CK signaling. Possibly, these effects are also mediated by

bacterial CK produced by these bacilli isolates for the purpose of their

interaction with the host plant they colonize, though further work is needed to

examine the role of bacterial CKs in this interaction and determine whether

plant developmental programs can be, directly or indirectly, altered by

Interestingly, age-related immunity was recently suggested to be microbiome status, could also relate to CK-mediated immunity, i.e., CK-mediated immunity is age-dependent, or age-dependent immunity is CK-mediated, depending on

Given its roles in growth and development, CK basically alters aging. In high

CK content, plants become more morphogenetic, meristems are supported for longer times, senescence is delayed, and thus, "juvenility" is retained, i.e., "aging" is delayed. This delay apparently causes a lengthening of the improved pathogen resistance (Gupta et al., 2020, 2021).

\section{CONCLUSION}

Analyzing developmental-age related changes in the phyllosphere microbiome, we observed a developmental age associated decline in microbial richness and diversity, accompanied by a decline in the presence of 
during aging, or prevent their loss from occurring. Additional work is needed to

\section{Acknowledgements}

The authors wish to thank Stefan J Green and Jonathan Friedman for helpful discussions, and the Bar and Jami group members for continuous discussion and support.

\section{Author contributions}

Conceptualization: MB. Design: $M B$ and RG. Methodology: RG, ML-M, EJ, and MB. Experimentation: RG, DE, ML-M and MB. Analysis: RG, DE, ML-M, EJ, and MB. Manuscript: RG and MB.

\section{Data availability Statement}

The authors declare that the data supporting the findings of this study are available within the paper and its Supplementary information files. Raw data is available through NCBI-SRA, Bioproject PRJNA729221.

\section{Competing Interests Statement}

The authors declare no competing interests.

\section{Supplemental material}

Figure S1: The amount of bacteria in the phyllosphere is CK dependent.

Figure S2: B. megaterium 4C induces differentiation of the flowering meristem.

Figure S3: B. megaterium 4C and B. pumilus R2E accelerate leaf development- Leaf complexity over time.

Table S1: qRT-PCR primers used in this work. 
bioRxiv preprint doi: https://doi.org/10.1101/2021.08.02.454802; this version posted August 2, 2021. The copyright holder for this preprint (which was not certified by peer review) is the author/funder, who has granted bioRxiv a license to display the preprint in perpetuity. It is made available under aCC-BY-NC-ND 4.0 International license. 


\section{METHODS}

Plant materials and sample collection

During the winter of 2018 , tomato leaf samples were collected from a roofed

net house, $2 \mathrm{~mm}$ nylon mesh net, in ARO, Volcani Institute, Rishon Lesion,

Israel. , Genotypes used, all in the cv. M82 background, were as follows: M82 background line; $p B L S » I P T 7$, which contains elevated endogenous levels of CK- referred to hereinafter as "pBLS»IPT" or "IPT"; clausa, which has increased CK sensitivity coupled with decreased CK content, referred to hereinafter as "clausa" or "clau"; and the CK depleted $p F I L \gg C K X 3$, referred to hereinafter as "pFIL»CKX" or "CKX" (Gupta et al., 2021).

\section{$16 S$ rRNA amplification, amplicon sequencing and bioinformatic 428 analysis

To examine whether plant developmental age affects tomato phyllosphere composition, phyllosphere microbial DNA was extracted from S. lycopersicum cv. M82 at various developmental ages. Plants were transplanted into the nethouse at randomly interspersed locations, and all samples were collected when the latest developmental stage was reached (for the oldest plants) on the same sampling date. For phyllosphere DNA isolation, five leaflet samples per sampling age were collected from the middle lateral leaflets of leaves 5-6 of 10 different plants per sample, using ethanol-sterilized forceps. Twenty $\mathrm{mL}$ of $0.1 \mathrm{M}$ potassium phosphate buffer at $\mathrm{pH} 8$ were added to the tubes. The samples were sonicated in a water bath for $2 \mathrm{~min}$ and vortexed for $30 \mathrm{~s}$ twice.

The pellet of microbes was obtained after centrifugation at 12,000 g for $20 \mathrm{~min}$ at $4^{\circ} \mathrm{C}$. The pellet re-suspended in potassium phosphate buffer (Gupta et al., 2021). Total DNA from tomato phyllosphere microorganisms was isolated using modified protocols described by (Yang et al., 2001) and (Tian et al., 2017), and used as a template for 16S rRNA PCR amplification. 16S rRNA 
CS2 806R:

TACGGTAGCAGAGACTTGGTCTGGACTACHVGGGTWTCT-'3 (Green et

al., 2015). Amplicon sequencing was conducted at the UIC core facility, using length trimming, chimera removal, clustering of sequences, annotation of clusters, and generation of a biological observation matrix (BIOM; sample-bytaxon abundance table). Taxonomy for the operational taxonomic units (OTUs) was assigned using BLAST against the Silva database (Glöckner et al., 2017) (silva_132_16S.97). Alpha and beta-diversity, and Shannon index, were performed with QIIME 1.9 as well the workflow script core_diversity_analysis.py. The sequence data generated in this study was deposited to the Sequence Read Archive (SRA) at NCBI under

\section{Quantification of leaf bacteria through DNA qPCR}

Total DNA extracts were used for quantification of specific genes using qPCR.

Total 16S rRNA and bacillus genes copy numbers were obtained using the 16S rRNA 515F/806R primer pair (515f: 5'- GTGCCAGCMGCCGCGGT-'3 and 806R: 5'-GGACTACHVGGGTWTCT-'3) (Green et al., 2015) and bacillus specific BacF/BacF (BacF: 5'- AGGGTCATTGGAAACTGGG-'3 and 806R: 5'CGTGTTGTAGCCCAGGTCATA-'3) (Kuske et al., 1998), respectively. The quantification was performed with a Rotor-Gene $Q$ machine (Qiagen) detection system and Power SYBR Green Master Mix protocol (Life Technologies, Thermo Fisher, United States). The standard regression curve was obtained using a $B$. megaterium 16S rRNA gene fragment and serial 1:10 dilutions. Four replicates of each standard dilution were prepared to generate a mean value. The standard regression curve was prepared to determine the gene copy numbers in the unknown samples, and numbers were normalized to the standard sample. All PCR reactions were performed in triplicates. 
Epiphytic bacteria were isolated and identified as described (Gupta et al., 480 2021). Accession numbers and details of bacterial isolates used in this study are provided in Table 1.

Table 1- bacterial isolates used in this work.

\begin{tabular}{|c|c|c|c|}
\hline$\underline{\mathrm{ID}}$ & $\underline{\text { Accession }}$ & Species & Source \\
\hline $4 C$ & MZ148746 & $\begin{array}{l}\text { Bacillus } \\
\text { megaterium }\end{array}$ & $p B L S>>I P T$ isolate \\
\hline R3C & MZ148747 & $\begin{array}{l}\text { Ralstonia } \\
\text { pickettii }\end{array}$ & $p B L S>>I P T$ isolate \\
\hline R2E & MZ148745 & $\begin{array}{l}\text { Bacillus } \\
\text { pumulis }\end{array}$ & $p B L S>>I P T$ isolate \\
\hline IN68 & -- & $\begin{array}{l}\text { Pseudomonas } \\
\text { aeruginosa }\end{array}$ & $\begin{array}{l}\text { Wheat phyllopshere isolate } \\
\text { obtained from__Jonathan } \\
\text { Friedman, Hebrew University of } \\
\text { Jerusalem }\end{array}$ \\
\hline SB491 & $\begin{array}{l}\text { SB491 } \\
\text { "legacy" } \\
\text { strain (Zeigler } \\
\text { et al., 2008; } \\
\text { Friedman et } \\
\text { al., 2017) }\end{array}$ & $\begin{array}{l}\text { Bacillus } \\
\text { subtilis }\end{array}$ & $\begin{array}{l}\text { Jonathan Friedman, Hebrew } \\
\text { University of Jerusalem }\end{array}$ \\
\hline
\end{tabular}

S. lycopersicum cv. M82 seeds were sown after surface sterilization (with $1.5 \% \mathrm{NaOCl}$ for five minutes, followed by three rinses with sterile water) in a tray containing potting mixture. After germination, a single tomato seedling was transplanted to each pot $(0.5 \mathrm{~L}$, diameter $=10 \mathrm{~cm})$ containing green temperature (Day- $20^{\circ} \mathrm{C}-26^{\circ} \mathrm{C}$; Night- $12^{\circ} \mathrm{C}-20^{\circ} \mathrm{C}$ ), 12-h photoperiod. Bacterial colonies of $B$. pumulis R2E, $B$. megaterium $4 \mathrm{C}, R$. pickettii R3C, $P$. aeruginosa IN68 and $B$. subtilis SB491 from a $24 \mathrm{~h}$ plate culture were washed twice in sterile distilled water, and then re-suspended in a $10 \mathrm{mM} \mathrm{MgCl} 2$ solution. The cell suspension was adjusted to an optical density of $\mathrm{OD}_{600}=0.1$ 


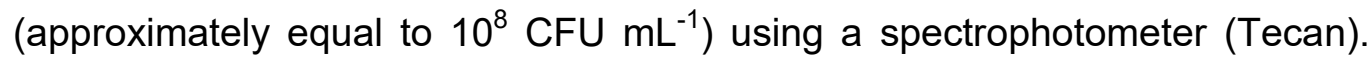

494

For mature plants (4-5 weeks old at the start of the experiment), soil

495

drenching of the plants was carried out by pouring $10 \mathrm{~mL}$ of bacterial

496

suspension into each pot once a week, for four weeks. For seedlings, plants

497

were spray-drenched using a hand-held spray bottle once a week, for two

498

weeks, starting from cotyledon emergence. Plants treated with sterile distilled

499

water served as controls.

500

501

Plant RNA preparation and qRT-PCR

502

RNA was isolated from liquid N2 ground shoot apices of 10 day old seedlings,

including the shoot apical meristem (SAM) and P1-P5 leaf primordia, of 12 to

504

15 seedlings individually treated with bacteria viz., $B$. pumulis R2E, $B$.

505

megaterium 4C, $R$. pickettii R3C, and $P$. aeruginosa IN68, using Tri reagent

506

(Sigma-Aldrich) as per the manufacturer's recommendations. RNA 507

concentrations were quantified, and cDNA was then synthesized from $2 \mu \mathrm{g} \quad 508$

RNA in a $20 \mu \mathrm{L}$ reaction, using both reverse transcriptase and oligo(dT) 509

primers provided with the cDNA Synthesis kit (Promega, United States). RT- 510

qPCR was performed according to the Power SYBR Green Master Mix 511

protocol (Life Technologies, Thermo Fisher, United States), using a Rotor- 512

Gene $Q$ machine (Qiagen) detection system. Primer sequences used for the 513

qRT-PCR analyses are detailed in Supplemental Table 1 (Gupta et al., 2020; 514

Bar et al., 2016). Expression of all assayed genes was normalized relative to 515

tomato a geometric mean of the copy number of the three housekeeping 516

genes, ribosomal protein SIRPL8 (Solyc10g006580), Slcyclophilin 517

(Solyc01g111170) and SIEXP (Solyc07g025390) was used for normalization. 518

All primer efficiencies were in the rage 0.98-1.03 (see supplementary Table 519

1). Relative expression was calculated using the copy number method for 520

gene expression (D’haene et al., 2010). 521

522

Seedling developmental analysis, dissection, and imaging

523 
Seedlings were harvested from soil by cutting them at the stem base. Height

524

from the stem base to the SAM, and weight were measured using a ruler and an analytical scale, respectively. The number of leaves was counted by dissecting the shoot under a stereomicroscope and counting all the initiated leaves, starting from P1. Differentiation of the meristem to floral and sympodial follows a predictable pattern in S. lycopersicum M82 (Park et al., 2012; Steiner et al., 2020), and was analyzed microscopically in dissected shoots.

Leaves are produced successively on the plant, and at a given time point each leaf is at a different developmental stage. Each leaf is thus characterized by both its position on the plant (for example, L1 is the first leaf produced and L5 is the fifth), and by its developmental stage. Thus, L5 P1 is the fifth leaf when it is at the P1 stage and has just initiated from the SAM, and it becomes L5 P2 after the next primordium initiates, and so on. For each developmental stage analyzed, the fifth leaf from at least ten different plants was analyzed for leaf complexity (the amount of leaflets). For analysis of TCSv2:3XVENUS expression, dissected whole-leaf primordia were placed into drops of water on glass microscope slides and covered with cover slips. The pattern of VENUS expression was observed with a Nikon SMZ-25 stereomicroscope equipped with a Nikon-D2 camera and NIS Elements v. 5.11 software (Steiner et al., 2020).

All experimental data is presented as minimum to maximum values with median or mean, in boxplots or floating bars, or as average $\pm S E M$, with all 548 points displayed. For microbiome analyses, differences between two groups 549 were analyzed for statistical significance using a Mann-Whitney test, or a two550 tailed t-test, with Welch's correction where applicable (unequal variances). 551 Differences among three groups or more were analyzed for statistical 552 significance with a Kruskal-Wallis ANOVA, with Dunn's multiple comparisons 553 post-hoc test. For all other analyses, differences between two groups were 554 analyzed for statistical significance using a two-tailed t-test, with Welch's 
correction where applicable (unequal variances), and differences among three 556

groups or more were analyzed for statistical significance with a one-way

ANOVA. Regular ANOVA was used for groups with equal variances, and

Welch's ANOVA for groups with unequal variances. When a significant result

for a group in an ANOVA was returned, significance in differences between

the means of different samples in the group were assessed using a post-hoc

test. The Tukey test was employed for samples with equal variances when the

mean of each sample was compared to the mean of every other sample. The

Bonferroni test was employed for samples with equal variances when the

mean of each sample was compared to the mean of a control sample. The

Dunnett test was employed for samples with unequal variances. All statistical 
bioRxiv preprint doi: https://doi.org/10.1101/2021.08.02.454802; this version posted August 2, 2021. The copyright holder for this preprint (which was not certified by peer review) is the author/funder, who has granted bioRxiv a license to display the preprint in perpetuity. It is made available under aCC-BY-NC-ND 4.0 International license. 


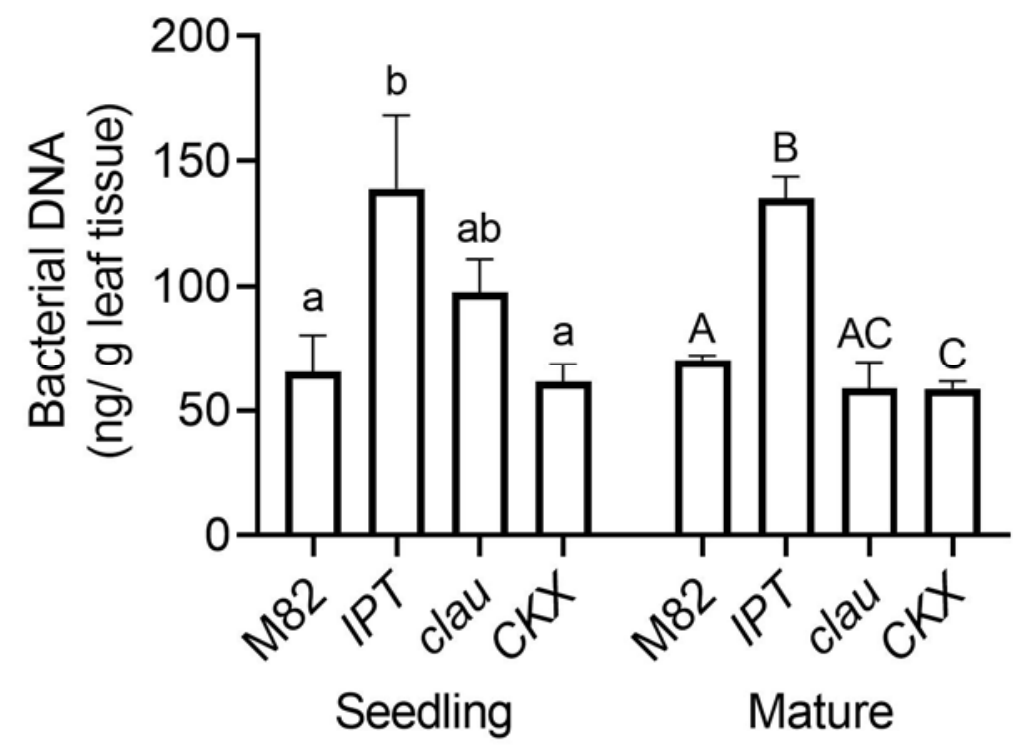

Figure S1. The amount of bacteria in the phyllosphere is CK dependent.

Bacterial DNA was extracted from indicated genotypes at the seedling and mature plant stages. Amount of bacterial DNA obtained per gram leaf tissues is plotted. Graphs depict mean \pm SE. Different letters indicate statistically significant differences in an unpaired two-tailed t-test with Welch's correction, $\mathrm{N}=10, p<0.05$. 


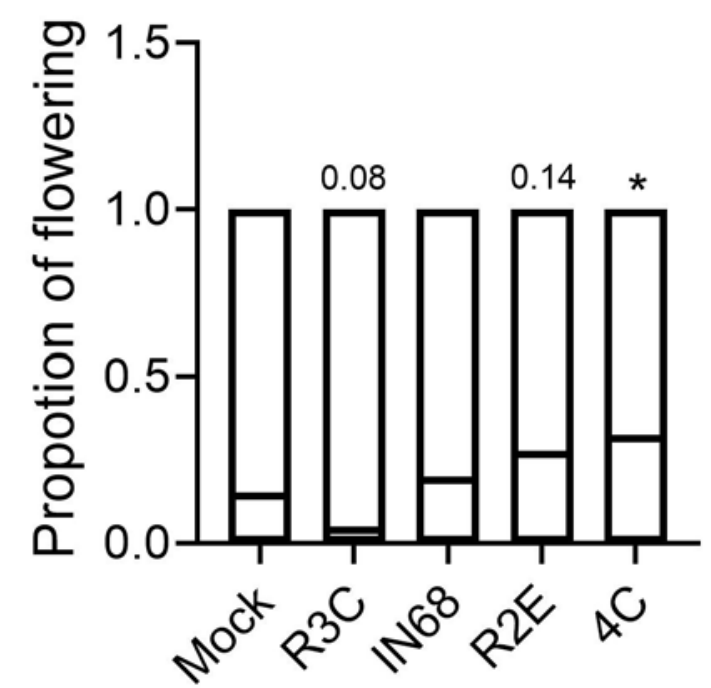

Figure S2: B. megaterium 4C induces differentiation of the flowering meristem.

Presence of the floral meristem was examined in 10 day old M82 mock and bacterial isolate treated seedlings. Floating bars depict minimum to maximum values, with lines indicating mean. Five independent experiments were conducted, $\mathrm{N}=30$. Asterisks represent statistical significance from mock treatment in a two-tailed t-test. ${ }^{*} p<0.05$. 


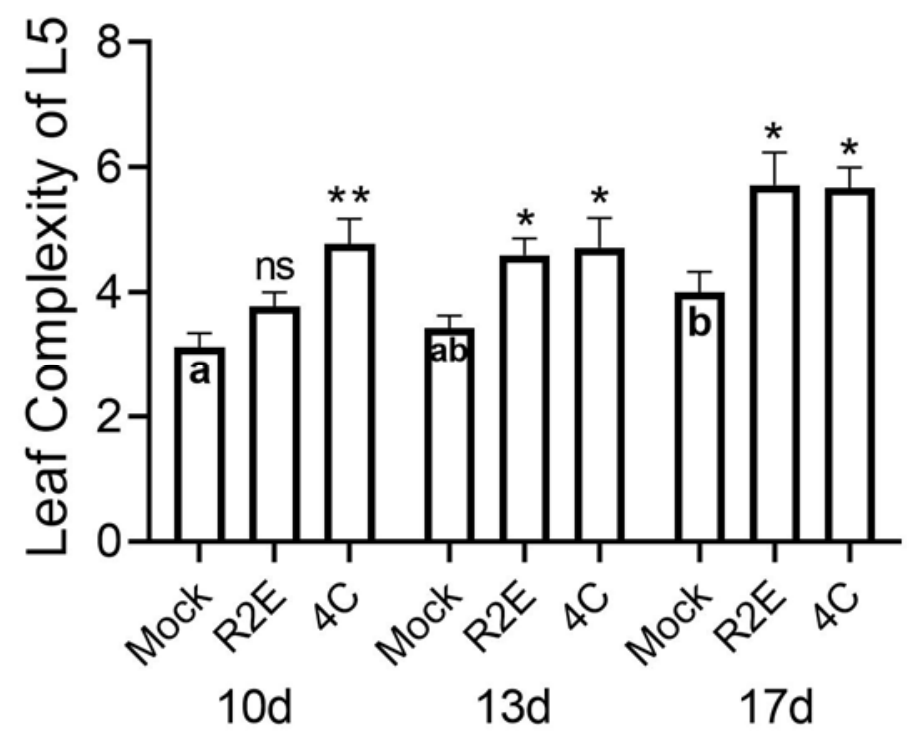

Figure S3: B. megaterium 4C and B. pumilus R2E accelerate leaf development- Leaf complexity over time.

Leaf complexity of the fifth leaf (L5) was measured in M82 mock, R2E, and 4C treated plants over time. Bars depict mean $\pm S E M$. Three independent experiments were conducted, $\mathrm{N}=10$ for each time point. Asterisks represent statistical significance from mock treatment, and different letters represent statistically significant differences among samples, in a two-tailed t-test. ${ }^{*} p<0.05,{ }^{* *} p<0.01$. 
Supplemental Table1 Primers used for qRT-PCR.

\begin{tabular}{|c|c|c|c|}
\hline Gene & Accession No. & Primer pairs $\left(5^{\prime}-3^{\prime}\right)$ & Efficiency \\
\hline PR1a (Pathogenesis & Solyc01g106620 & F: CTGGTGCTGTGAAGATGTGG & 0.98 \\
\hline related-1a) & & R: TGACCCTAGCACAACCAAGA & \\
\hline \multirow[t]{2}{*}{ LoxD } & Solyc03g122340 & F: CCATCCTCACCACCCTCATC & 0.97 \\
\hline & & R: TACTCGGGATCGTTCTCGTC & \\
\hline \multirow[t]{2}{*}{ IPT3 } & Solyc01g080150 & F: TTCCATGCTTGATGTGCTTC & 0.98 \\
\hline & & R: GCTTGCTGTCAACGTCAAAA & \\
\hline \multirow[t]{2}{*}{ CKX2 } & Solyc01g088160 & F: CCCCGAAAATGGTGAAATG & 1.01 \\
\hline & & R: CAAAGTGGCTTGCTTGAACA & \\
\hline \multirow[t]{2}{*}{ TKN2 } & Solyc02g081120 & F: CCATATCCATCGGAATCTCAG & 1.00 \\
\hline & & R: TGGTTTCCAATGCCTCTTTC & \\
\hline \multirow[t]{2}{*}{ CKX5 } & Solyc04g016430 & F: TGTCACTGGTAAAGGAGAGGTG & 1.02 \\
\hline & & R: GAGCAATCCTAGCCCTTGTG & \\
\hline \multirow[t]{2}{*}{ CKX6 } & Solyc12g008900 & F: CAGGTGCTAAGCCATACTCTAGG & 1.03 \\
\hline & & R: GGACATTCCATTAGGGGACA & \\
\hline \multirow[t]{2}{*}{ CLAU } & Solyc04g008480 & F: CCTCTCACAACAAGCAATGAACTT & 0.97 \\
\hline & & R: AGGACGATGCAATGAGAGAGAC & \\
\hline \multirow[t]{2}{*}{ GOBLET } & Solyc07g062840 & F: CAGGAGTTCGAAGGACGAGTGG & 1.00 \\
\hline & & R: TTGGCTGTAGTGTATGCAAGGTG & \\
\hline \multirow[t]{2}{*}{ TRR3/4 } & Solyc05g006420 & F: CGTCCCCTAAAGCATTCTCA & 0.98 \\
\hline & & R: CGTCTTGTTGGTGATGTTGG & \\
\hline \multirow[t]{2}{*}{ EXP (Expressed) } & Solyc07g025390 & F: TGGGTGTGCCTTTCTGAATG & 1.00 \\
\hline & & R: GCTAAGAACGCTGGACCTAATG & \\
\hline RPL8 (Ribosomal & Solyc10g006580 & F: TGGAGGGCGTACTGAGAAAC & 1.03 \\
\hline protein L2) & & R: TCATAGCAACACCACGAACC & \\
\hline \multirow[t]{2}{*}{ CYP (Cyclophilin) } & Solyc01g111170 & F: TGAGTGGCTCAACGGAAAGC & 1.03 \\
\hline & & R: CCAACAGCCTCTGCCTTCTTA & \\
\hline
\end{tabular}




\section{Parsed Citations}

Albacete, A, Ghanem, M.E., Martinez-Andujar, C., Acosta, M., Sanchez-Bravo, J., Martinez, V., Lutts, S., Dodd, I.C., and Perez-Alfocea, F. (2008). Hormonal changes in relation to biomass partitioning and shoot growth impairment in salinized tomato (Solanum lycopersicum L.) plants. Journal of Experimental Botany 59.

Google Scholar: Author Only Title Only Author and Title

Bar, M., Ben-Herzel, O., Kohay, H., Shtein, I., and Ori, N. (2015). CLAUSA restricts tomato leaf morphogenesis and GOBLET expression. The Plant Journal 83.

Google Scholar: Author Only Title Only Author and Title

Bar, M., Israeli, A, Levy, M., ben Gera, H., Jiménez-Gómez, J., Kouril, S., Tarkowski, P., and Ori, N. (2016). CLAUSA is a MYB Transcription Factor that Promotes Leaf Differentiation by Attenuating Cytokinin Signaling. The Plant Cell.

Google Scholar: Author Only Title Only Author and Title

Bartrina, I., Otto, E., Strnad, M., Werner, T., and Schmülling, T. (2011). Cytokinin Regulates the Activity of Reproductive Meristems,

Flower Organ Size, Ovule Formation, and Thus Seed Yield in Arabidopsis thaliana. The Plant Cell 23.

Google Scholar: Author Only Title Only Author and Title

Berens, M.L. et al. (2019). Balancing trade-offs between biotic and abiotic stress responses through leaf age-dependent variation in stress hormone cross-talk. Proceedings of the National Academy of Sciences 116.

Google Scholar: Author Only Title Only Author and Title

Berger, Y., Harpaz-Saad, S., Brand, A, Melnik, H., Sirding, N., Alvarez, J.P., Znder, M., Samach, A, Eshed, Y., and Ori, N. (2009). The NAC-domain transcription factor GOBLET specifies leaflet boundaries in compound tomato leaves. Development 136.

Google Scholar: Author Only Title Only Author and Title

Bodenhausen, N., Bortfeld-Miller, M., Ackermann, M., and Vorholt, J.A (2014). A Synthetic Community Approach Reveals Plant Genotypes Affecting the Phyllosphere Microbiota. PLoS Genetics 10.

Google Scholar: Author Only Title Only Author and Title

Busta, L., Hegebarth, D., Kroc, E., and Jetter, R. (2017). Changes in cuticular wax coverage and composition on developing

Arabidopsis leaves are influenced by wax biosynthesis gene expression levels and trichome density. Planta 245.

Google Scholar: Author Only Title Only Author and Title

Caporaso, J.G. et al. (2010). QIIME allows analysis of high-throughput community sequencing data. Nature Methods 7.

Google Scholar: Author Only Title Only Author and Title

Chaparro, J.M., Badri, D. v, and Vivanco, J.M. (2014). Rhizosphere microbiome assemblage is affected by plant development. The ISME Journal 8.

Google Scholar: Author Only Title Only Author and Title

Chen, T. et al. (2020). A plant genetic network for preventing dysbiosis in the phyllosphere. Nature 580.

Google Scholar: Author Only Title Only Author and Title

Cordovez, V., Rotoni, C., Dini-Andreote, F., Oyserman, B., Carrión, V.J., and Raaijmakers, J.M. (2021). Successive plant growth amplifies genotype-specific assembly of the tomato rhizosphere microbiome. Science of The Total Environment 772.

Google Scholar: Author Only Title Only Author and Title

Davey, J.E. and van Staden, J. (1976). Cytokinin translocation: Changes in zeatin and zeatin-riboside levels in the root exudate of tomato plants during their development. Planta 130.

Google Scholar: Author Only Title Only Author and Title

DeMason, D.A (2005). Auxin-cytokinin and auxin-gibberellin interactions during morphogenesis of the compound leaves of pea (Pisum sativum). Planta 222.

Google Scholar: Author Only Title Only Author and Title

Develey-Rivière, M. and Galiana, E. (2007). Resistance to pathogens and host developmental stage: a multifaceted relationship within the plant kingdom New Phytologist 175.

Google Scholar: Author Only Title Only Author and Title

D'haene, B. et al. (2010). FOXL2 copy number changes in the molecular pathogenesis of BPES: unique cohort of 17 deletions. Human Mutation.

Google Scholar: Author Only Title Only Author and Title

Dimopoulou, A, Theologidis, I., Liebmann, B., Kalantidis, K., Vassilakos, N., and Skandalis, N. (2019). Bacillus amyloliquefaciens MBI600 differentially induces tomato defense signaling pathways depending on plant part and dose of application. Scientific Reports 9.

Google Scholar: Author Only Title Only Author and Title

French, E., Kaplan, I., Iyer-Pascuzzi, A, Nakatsu, C.H., and Enders, L. (2021). Emerging strategies for precision microbiome management in diverse agroecosystems. Nature Plants 7.

Google Scholar: Author Only Title Only Author and Title 

available under aCC-BY-NC-ND 4.0 International license.

Friedman, J., Higgins, L.M., and Gore, J. (2017). Community structure follows simple assembly rules in microbial microcosms. Nature Ecology \& Evolution 1.

Google Scholar: Author Only Title Only Author and Title

Glöckner, F.O., Yilmaz, P., Quast, C., Gerken, J., Beccati, A, Ciuprina, A, Bruns, G., Yarza, P., Peplies, J., Westram, R., and Ludwig, W. (2017). 25 years of serving the community with ribosomal RNAgene reference databases and tools. Journal of Biotechnology 261.

Google Scholar: Author Only Title Only Author and Title

Green, S.J., Venkatramanan, R., and Naqib, A (2015). Deconstructing the Polymerase Chain Reaction: Understanding and Correcting Bias Associated with Primer Degeneracies and Primer-Template Mismatches. PLOS ONE 10.

Google Scholar: Author Only Title Only Author and Title

Gupta, R., Elkabetz, D., Leibman-Markus, M., Sayas, T., Schneider, A, Jami, E., Kleiman, M., and Bar, M. (2021). Cytokinin drives assembly of the phyllosphere microbiome and promotes disease resistance through structural and chemical cues. The ISME Journal. Google Scholar: Author Only Title Only Author and Title

Gupta, R., Pizarro, L., Leibman-Markus, M., Marash, I., and Bar, M. (2020). Cytokinin response induces immunity and fungal pathogen resistance, and modulates trafficking of the PRR LeEIX2 in tomato. Molecular Plant Pathology 21.

Google Scholar: Author Only Title Only Author and Title

Hagemann, W. and Gleissberg, S. (1996). Organogenetic capacity of leaves: The significance of marginal blastozones in angiosperms. Plant Systematics and Evolution 199.

Google Scholar: Author Only Title Only Author and Title

Israeli, A, Burko, Y., Shleizer-Burko, S., Zelnik, I.D., Sela, N., Hajirezaei, M.R., Fernie, AR., Tohge, T., Ori, N., and Bar, M. (2021). Coordinating the morphogenesis-differentiation balance by tweaking the cytokinin-gibberellin equilibrium PLOS Genetics 17. Google Scholar: Author Only Title Only Author and Title

Kaminek, M., Motyka, V., and Vankova, R. (1997). Regulation of cytokinin content in plant cells. Physiologia Plantarum 101.

Google Scholar: Author Only Title Only Author and Title

Karasov, T.L., Chae, E., Herman, J.J., and Bergelson, J. (2017). Mechanisms to Mitigate the Trade-Off between Growth and Defense. The Plant Cell 29.

Google Scholar: Author Only Title Only Author and Title

Kieber, J.J. and Schaller, G.E. (2018). Cytokinin signaling in plant development. Development 145.

Google Scholar: Author Only Title Only Author and Title

Koskella, B. (2020). The phyllosphere. Current Biology 30.

Google Scholar: Author Only Title Only Author and Title

Kremer, J.M., P.B.C., R.D., T.C., F.J.E., S.-L.P., T.J.M. and H.S.Y. (2018). FlowPot axenic plant growth system for microbiota research. bioRxiv: 254953-undefined.

Google Scholar: Author Only Title Only Author and Title

Kuske, C.R., Banton, K.L., Adorada, D.L., Stark, P.C., Hill, K.K., and Jackson, P.J. (1998). Small-Scale DNASample Preparation Method for Field PCR Detection of Microbial Cells and Spores in Soil. Applied and Environmental Microbiology 64.

Google Scholar: Author Only Title Only Author and Title

Leveau, J.H. (2019). A brief from the leaf: latest research to inform our understanding of the phyllosphere microbiome. Current Opinion in Microbiology 49.

Google Scholar: Author Only Title Only Author and Title

Li, H. et al. (2013). Cytokinin signaling regulates pavement cell morphogenesis in Arabidopsis. Cell Research 23.

Google Scholar: Author Only Title Only Author and Title

Li, P., Lu, Y.-J., Chen, H., and Day, B. (2020). The Lifecycle of the Plant Immune System. Critical Reviews in Plant Sciences 39. Google Scholar: Author Only Title Only Author and Title

Liu, H., Brettell, L.E., and Singh, B. (2020). Linking the Phyllosphere Microbiome to Plant Health. Trends in Plant Science 25. Google Scholar: Author Only Title Only Author and Title

Li, Y., Zhang, Z, Liu, W., Ke, M., Qu, Q., Zhou, Z, Lu, T., and Qian, H. (2021). Phyllosphere bacterial assemblage is affected by plant genotypes and growth stages. Microbiological Research 248.

Google Scholar: Author Only Title Only Author and Title

Maignien, L., DeForce, E.A, Chafee, M.E., Eren, AM., and Simmons, S.L. (2014). Ecological Succession and Stochastic Variation in the Assembly of Arabidopsis thaliana Phyllosphere Communities. mBio 5.

Google Scholar: Author Only Title Only Author and Title

Manching, H.C., Carlson, K., Kosowsky, S., Smitherman, C.T., and Stapleton, AE. (2018). Maize Phyllosphere Microbial Community Niche Development Across Stages of Host Leaf Growth. F1000Research 6.

Google Scholar: Author Only Title Only Author and Title 

available under aCC-BY-NC-ND 4.0 International license.

Marsch-Martínez, N., Ramos-Cruz, D., Irepan Reyes-Olalde, J., Lozano-Sotomayor, P., Zúñiga-Mayo, V.M., and de Folter, S. (2012). The role of cytokinin during Arabidopsis gynoecia and fruit morphogenesis and patterning. The Plant Journal 72.

Google Scholar: Author Only Title Only Author and Title

McCall, A.C. and Fordyce, J.A (2010). Can optimal defence theory be used to predict the distribution of plant chemical defences? Journal of Ecology 98.

Miljaković, D., Marinković, J., and Balešević-Tubić, S. (2020). The Significance of Bacillus spp. in Disease Suppression and Growth Promotion of Field and Vegetable Crops. Microorganisms 8.

Google Scholar: Author Only Title Only Author and Title

Moroenyane, I., Mendes, L., Tremblay, J., Tripathi, B., and Yergeau, É. (2021). Plant Compartments and Developmental Stages Modulate the Balance between Niche-Based and Neutral Processes in Soybean Microbiome. Microbial Ecology.

Google Scholar: Author Only Title Only Author and Title

Nikolić, R., Mitić, N., Miletić, R., and Nešković, M. (2006). Effects of Cytokinins on In Vitro Seed Germination and Early Seedling Morphogenesis in Lotus corniculatus L. Journal of Plant Growth Regulation 25.

Google Scholar: Author Only Title Only Author and Title

Nordstrom, A, Tarkowski, P., Tarkowska, D., Norbaek, R., Astot, C., Dolezal, K., and Sandberg, G. (2004). Auxin regulation of cytokinin biosynthesis in Arabidopsis thaliana: A factor of potential importance for auxin-cytokinin-regulated development. Proceedings of the National Academy of Sciences 101.

Google Scholar: Author Only Title Only Author and Title

Park, S.J., Jiang, K., Schatz, M.C., and Lippman, ZB. (2012). Rate of meristem maturation determines inflorescence architecture in tomato. Proceedings of the National Academy of Sciences 109.

Google Scholar: Author Only Title Only Author and Title

Redford, AJ., Bowers, R.M., Knight, R., Linhart, Y., and Fierer, N. (2010). The ecology of the phyllosphere: geographic and phylogenetic variability in the distribution of bacteria on tree leaves. Environmental Microbiology 12.

Google Scholar: Author Only Title Only Author and Title

Shani, E., Ben-Gera, H., Shleizer-Burko, S., Burko, Y., Weiss, D., and Ori, N. (2010). Cytokinin Regulates Compound Leaf Development in Tomato. The Plant Cell 22.

Google Scholar: Author Only Title Only Author and Title

Shwartz, I., Levy, M., Ori, N., and Bar, M. (2016). Hormones in tomato leaf development. Developmental Biology 419.

Google Scholar: Author Only Title Only Author and Title

Steiner, E., Israeli, A, Gupta, R., Shwartz, I., Nir, I., Leibman-Markus, M., Tal, L., Farber, M., Amsalem, Z, Ori, N., Müller, B., and Bar, M. (2020). Characterization of the cytokinin sensor TCSv2 in arabidopsis and tomato. Plant Methods 16.

Google Scholar: Author Only Title Only Author and Title

Tian, X., Shi, Y., Geng, L., Chu, H., Zhang, J., Song, F., Duan, J., and Shu, C. (2017). Template Preparation Affects 16S rRNA High-

Throughput Sequencing Analysis of Phyllosphere Microbial Communities. Frontiers in Plant Science 8.

Google Scholar: Author Only Title Only Author and Title

Vorholt, J.A (2012). Microbial life in the phyllosphere. Nature Reviews Microbiology 10.

Google Scholar: Author Only Title Only Author and Title

Wagner, M.R., Lundberg, D.S., del Rio, T.G., Tringe, S.G., Dangl, J.L., and Mitchell-Olds, T. (2016). Host genotype and age shape the leaf and root microbiomes of a wild perennial plant. Nature Communications 7.

Google Scholar: Author Only Title Only Author and Title

Wilkens, R.T., Shea, G.O., Halbreich, S., and Stamp, N.E. (1996). Resource availability and the trichome defenses of tomato plants. Oecologia 106.

Google Scholar: Author Only Title Only Author and Title

Williams, T.R., Moyne, A-L., Harris, L.J., and Marco, M.L. (2013). Season, Irrigation, Leaf Age, and Escherichia coli Inoculation Influence the Bacterial Diversity in the Lettuce Phyllosphere. PLoS ONE 8.

Google Scholar: Author Only Title Only Author and Title

Yang, C.-H., Crowley, D.E., Borneman, J., and Keen, N.T. (2001). Microbial phyllosphere populations are more complex than previously realized. Proceedings of the National Academy of Sciences 98.

Google Scholar: Author Only Title Only Author and Title

Zeier, J. (2005). Age-dependent variations of local and systemic defence responses in Arabidopsis leaves towards an avirulent strain of Pseudomonas syringae. Physiological and Molecular Plant Pathology 66.

Google Scholar: Author Only Title Only Author and Title

Zeigler, D.R., Prágai, Z, Rodriguez, S., Chevreux, B., Muffler, A., Albert, T., Bai, R., Wyss, M., and Perkins, J.B. (2008). The Origins of 168, W23, and Other Bacillus subtilis Legacy Strains. Journal of Bacteriology 190.

Google Scholar: Author Only Title Only Author and Title 
bioRxiv preprint doi: https://doi.org/10.1101/2021 08.02 454802; this version posted August 2, 2021. The copyright holder for this preprint which was not certified by peer review) is the author/funder, who has granted bioRxiv a license to display the preprint in perpetuity. It is made available under aCC-BY-NC-ND 4.0 International license.

Zürcher, E., Tavor-Deslex, D., Lituiev, D., Enkerli, K., Tarr, P.T., and Müller, B. (2013). ARobust and Sensitive Synthetic Sensor to Monitor the Transcriptional Output of the Cytokinin Signaling Network in Planta . Plant Physiology 161.

Google Scholar: Author Only Title Only Author and Title 